\title{
三/A Blocking local glucocorticoid activation \\ UCSF \\ improves skin thinning and impaired wound healing in Cushingoid mice
}

\section{Ana Tiganescu, Melanie Hupe, Yoshikazu Uchida, Peter M. Elias and Walter M. Holleran}

VA Medical Center (NCIRE), University of California San Francisco

\section{Introduction \\ Cushing's disease presents with multiple symptoms of systemic glucocorticoid (GC) excess including increased skin thinning and poor wound healing $(\mathrm{WH})$. \\ Local GC concentrations are regulated by $11 \beta$-hydroxysteroid dehydrogenase type 1 (11ß-HSD1) which activates cortisol or corticosterone from cortisone or 11- dehydrocorticosterone in human or mouse tissues respectively, including skin (Fig. 1). We recently demonstrated elevate HSD1 activity during early WH (Tiganescu $e$ al. 2014). Here, we hypothesize that local 11ß-HSD1 blockade improves the WH delay caused by systemic GC excess.

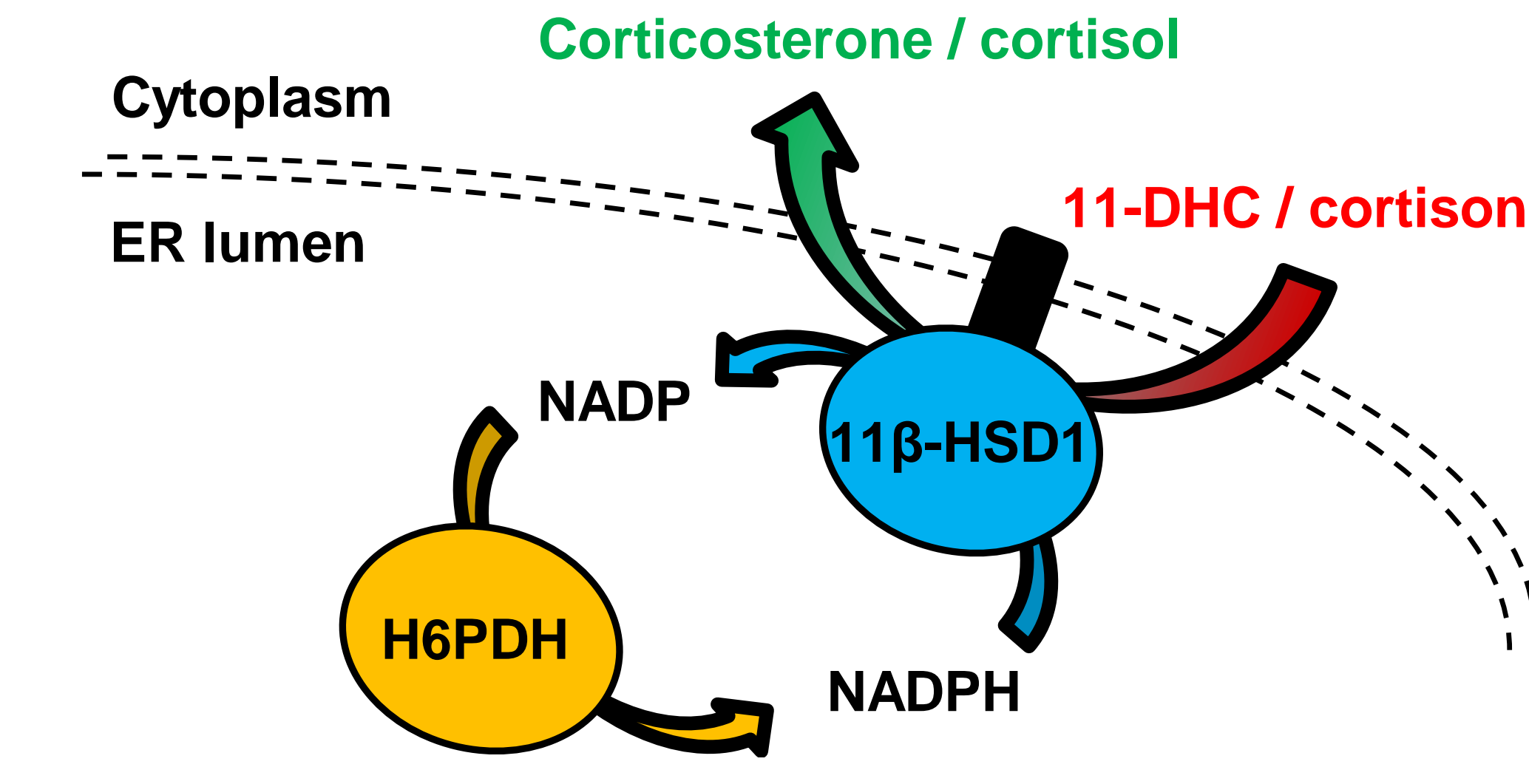

Fig. 1. GC activation by 11ß-HSD1 requires NADPH co-factor supplied

\section{Methods}

We examined the effects of systemic GC excess (or vehicle) in female SKH1 mice which developed Cushingoid features and suppressed endogenous serum corticosterone vs. vehicle $(5.5$ vs. $18.5 \mathrm{ng} / \mathrm{ml}, \mathrm{p}<0.01)$ over 5 weeks corticosterone (CORT) therapy $(100 \mu \mathrm{g} / \mathrm{ml}$ in drinking water). Mice were treated bi-daily with $30 \mathrm{mM}(200 \mu \mathrm{g})$ topical carbenoxolone (CBX, 11ß-HSD1 inhibitor) or vehicle (VEH), one week prior to and postwounding (by double $5 \mathrm{~mm}$ dorsal biopsy).

\section{Results}

1. 11ß-HSD1 blockade did not affect skin function in young healthy SKH1 female mice

CBX treatment inhibited 11 $\beta$-HSD1 activity by $70 \%$ before wounding ( $\mathrm{Fig} .2 \mathrm{2}$ ) and $>90 \%$ during WH (Fig. 2b).

$11 \beta$-HSD1 inhibition did not affect epiderma thickness (Fig. 3a).
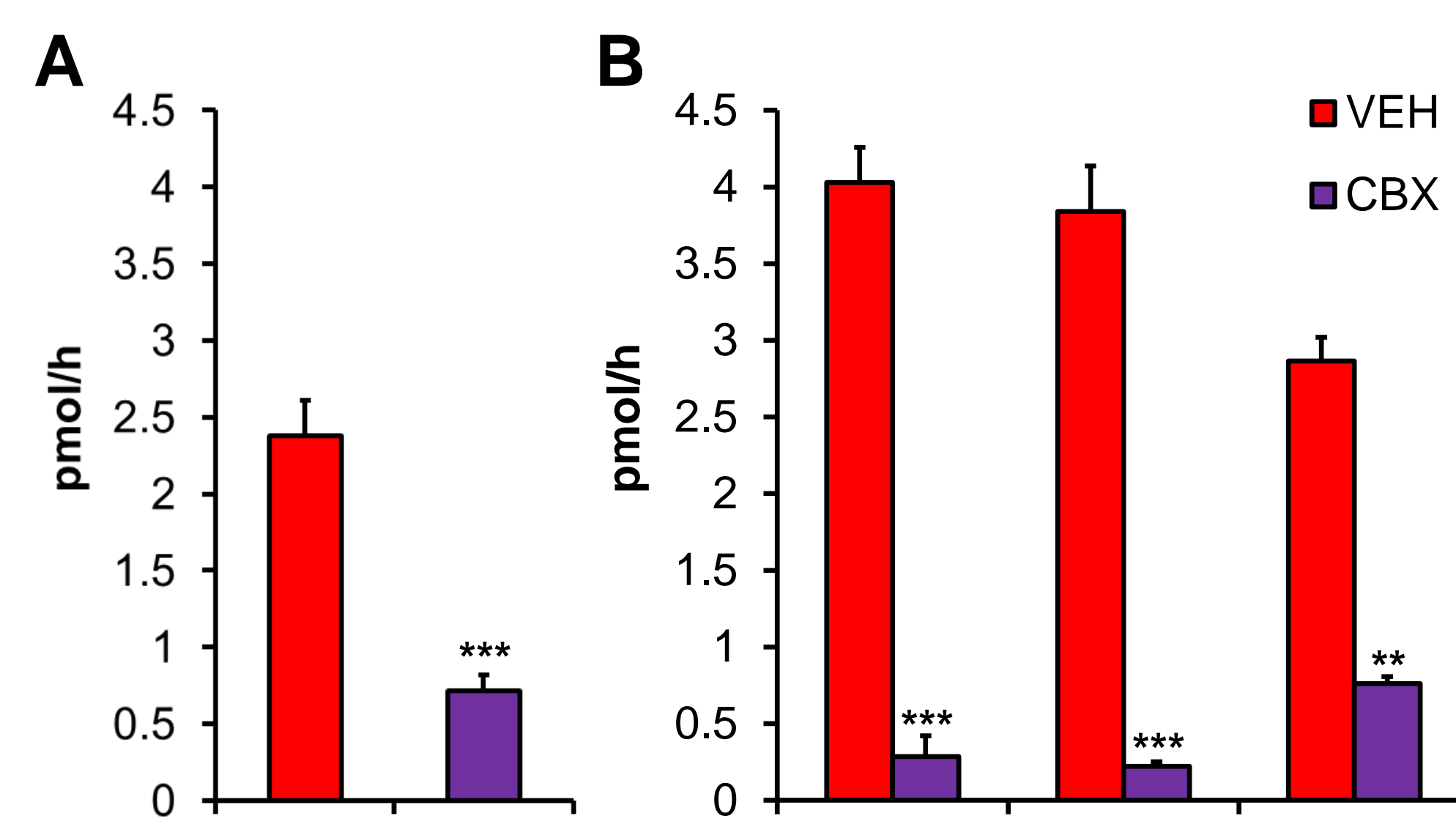

Day post

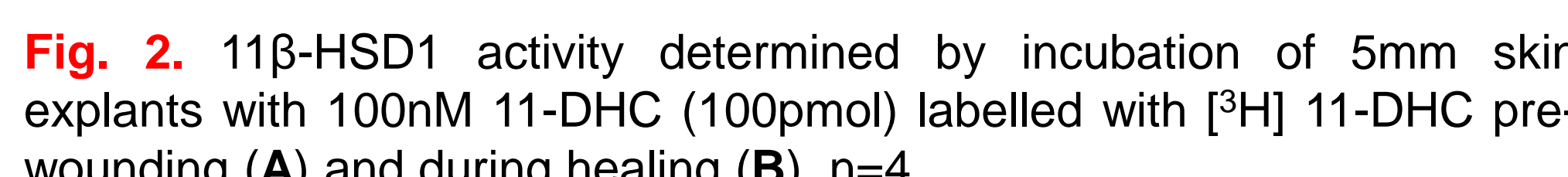

CBX treatment did not affect transepidermal water loss (TEWL; a measure of epidermal barrier integrity) neither before disruption by tape stripping nor during subsequent recovery (Fig. 3b). The number of tape strips required for disruption was unaffected by $\mathrm{CBX}$ treatment (VEH $3.3 \pm 0.1$ S.E vs. CBX $3.2 \pm 0.1$ ). Wound healing rate was also unaffected by CBX (Fig. 3C)

2. Systemic GC excess induces GC activation in skin

$11 \beta$-HSD1 activity in unwounded CORT skin was $42 \%$ higher than $\mathrm{VEH}$ and was inhibited $>60 \%$ by CBX (Fig. 4a), supported by elevated $11 \beta$-HSD1 mRNA pre- and post-wounding (Fig. 4b). H6PDH and glucocorticoid receptor mRNA were also upregulated (Fig. 4c, 4d).

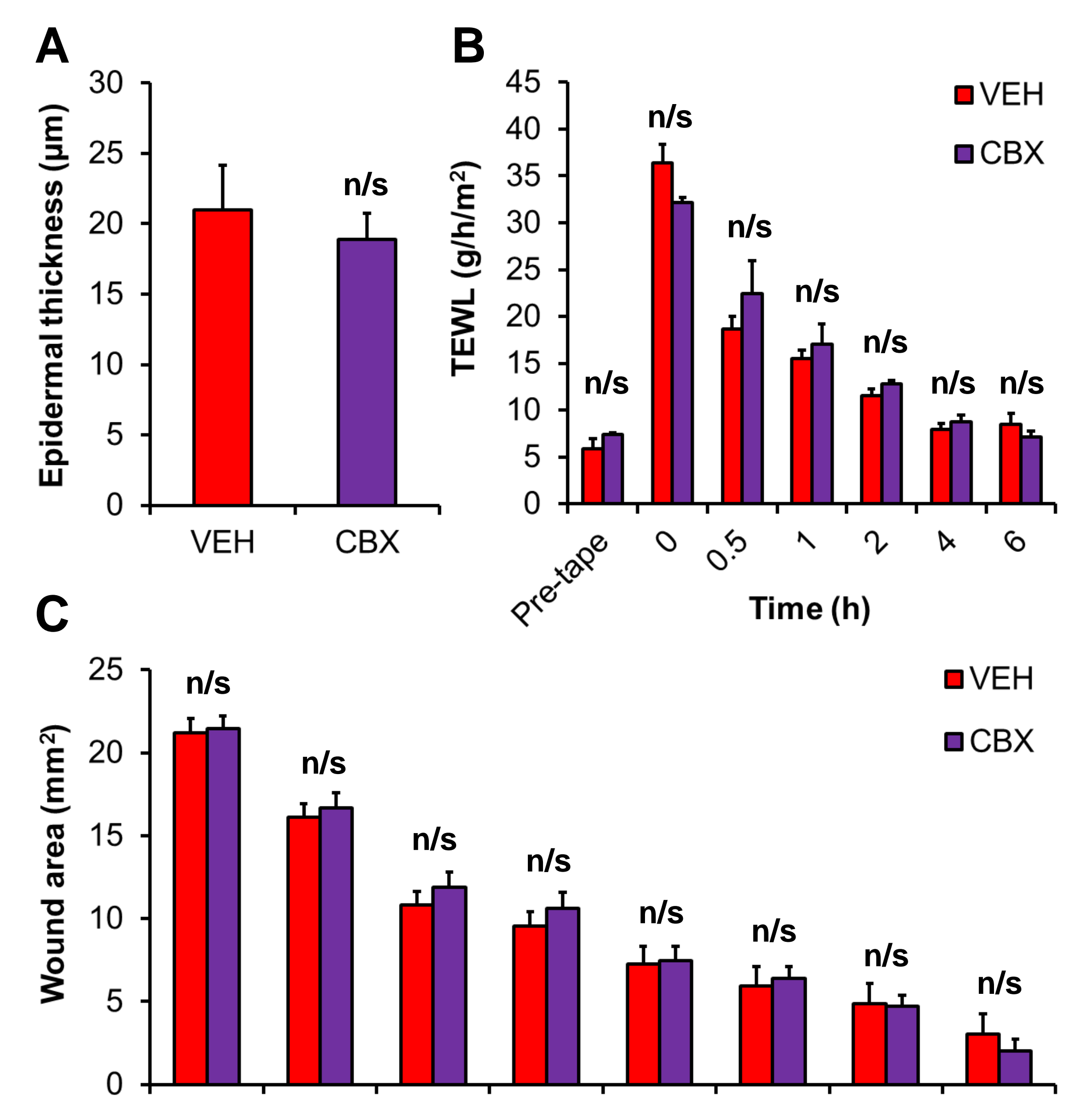

Fig. 3. $11 \beta$-HSD1 inhibition did not affect epidermal thickness $(\mathbf{A}, \mathrm{n}=4)$,
pre-disruption transepidermal water loss and recovery following tape
stripping $(\mathbf{B}, \mathrm{n}=4)$ or wound healing $(\mathbf{C}, \mathrm{n}=8-24)$ in healthy $S \mathrm{SH} 1$ mice A
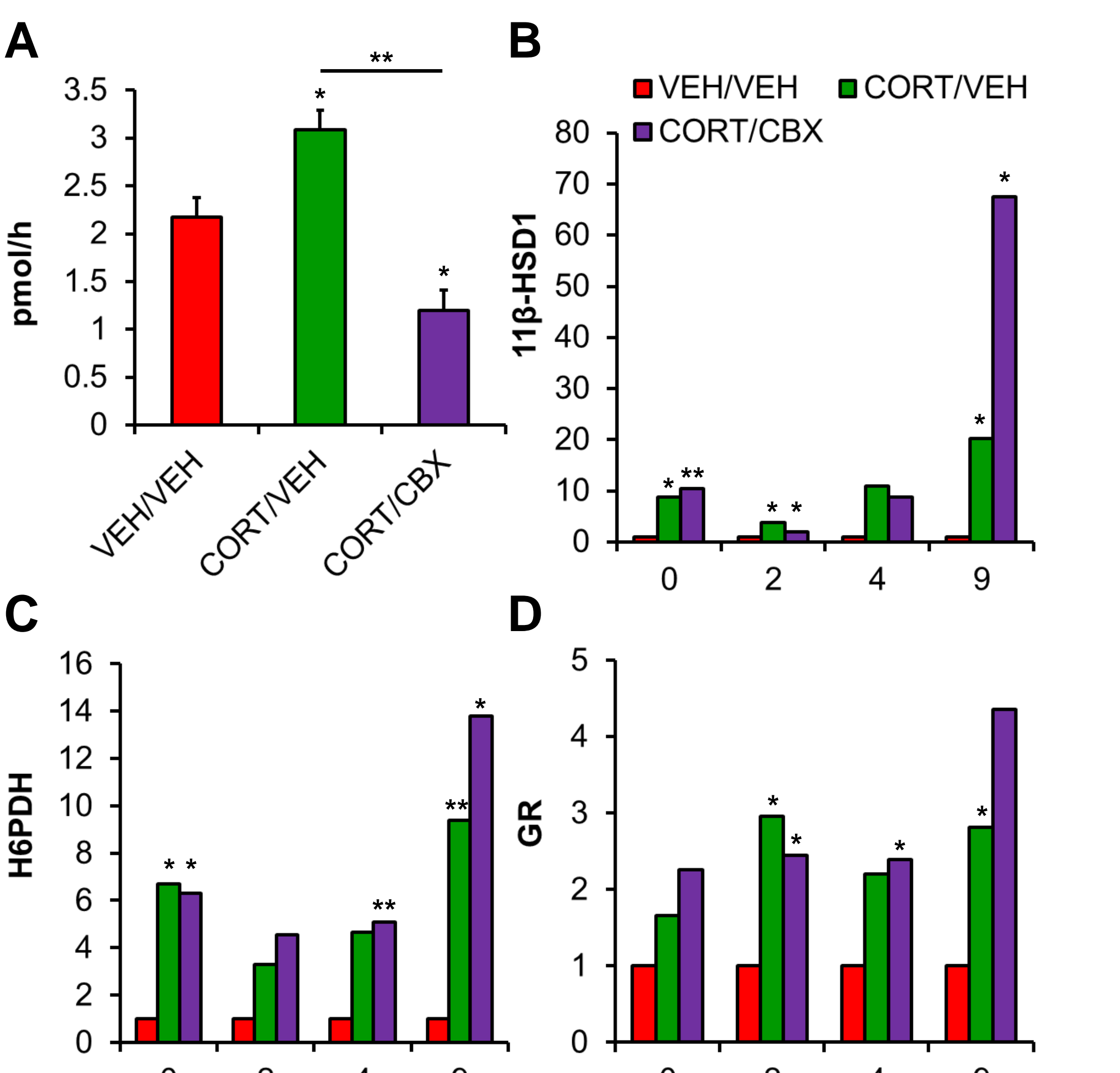

Day post-wounding

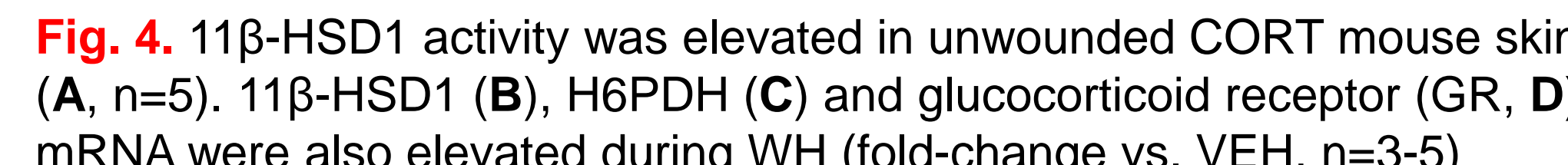

3. Detrimental consequences of systemic GC excess on epidermis are improved by topical 11 $\beta$-HSD1 blockade

Epidermal thinning induced by CORT treatment was reduced by $35 \%$ with CBX (Fig $5 a, 5 b)$.

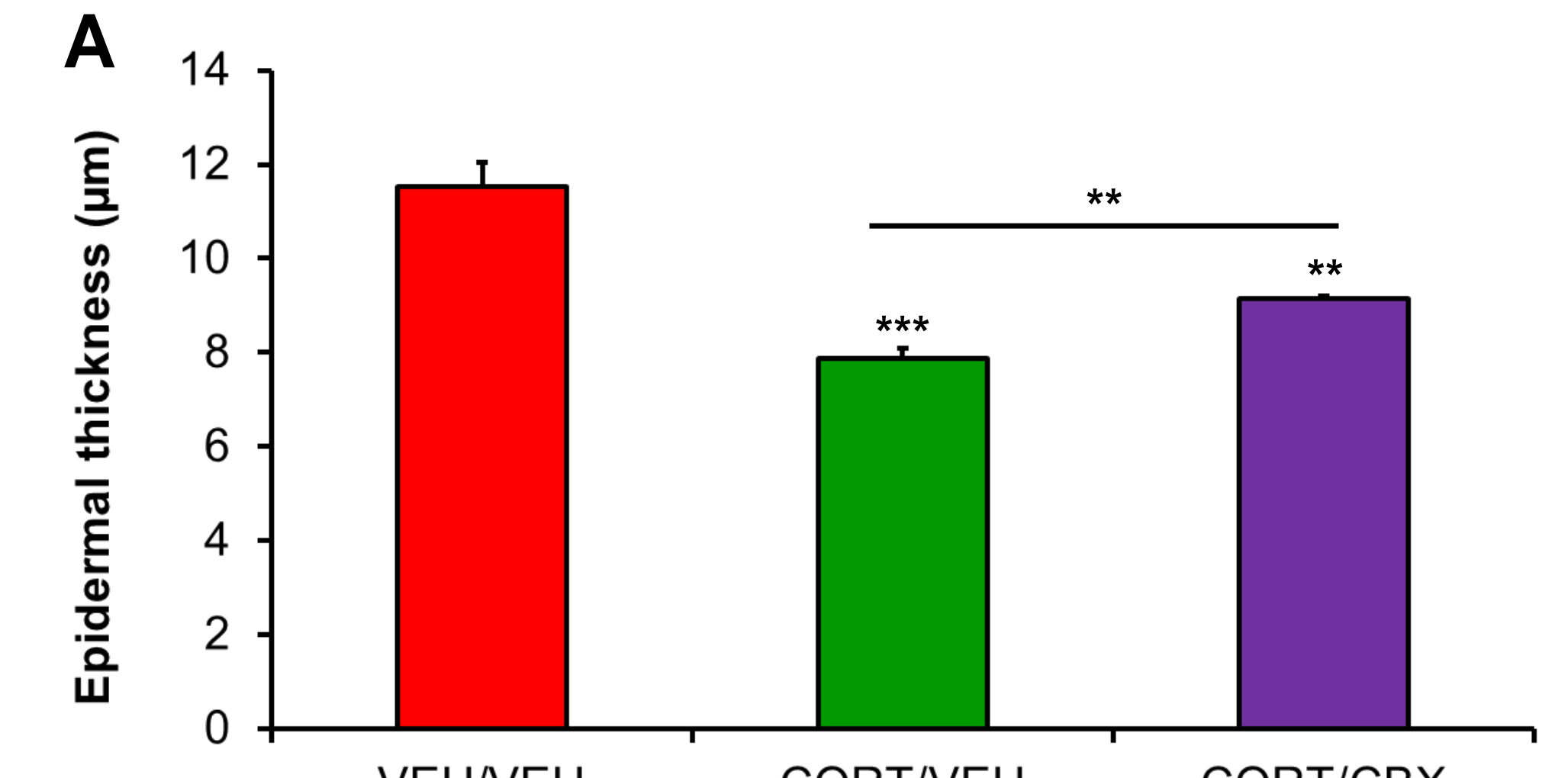

B
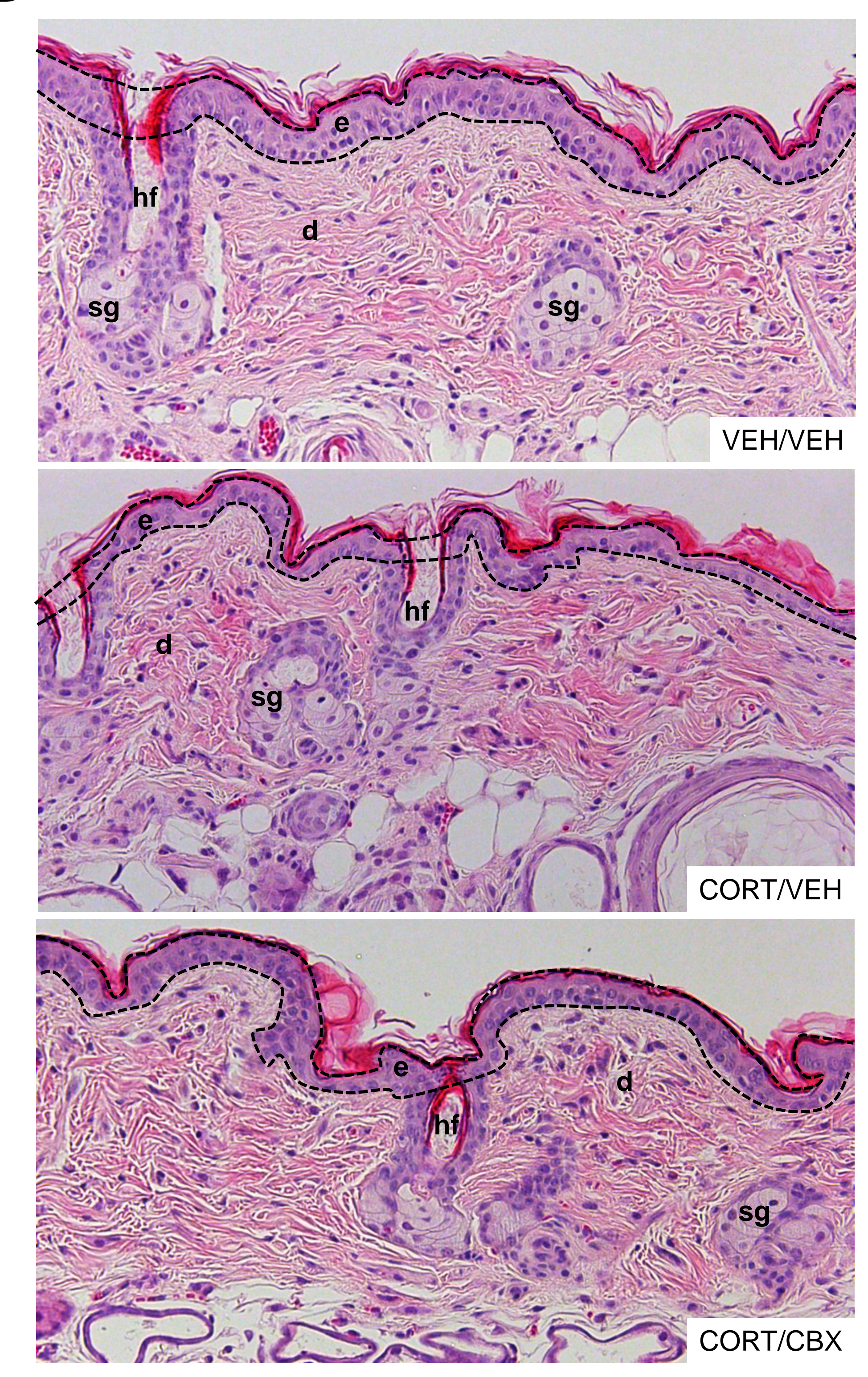



Systemic GC excess did not influence resting TEWL, nor recovery following disruption (Fig. 6a). However, CORT-treated skin was more resistant to tape stripping, requiring 2.7 more tapes to induce TEWL comparable to $\mathrm{VEH}$. This was normalized by CBX (Fig. 6b).

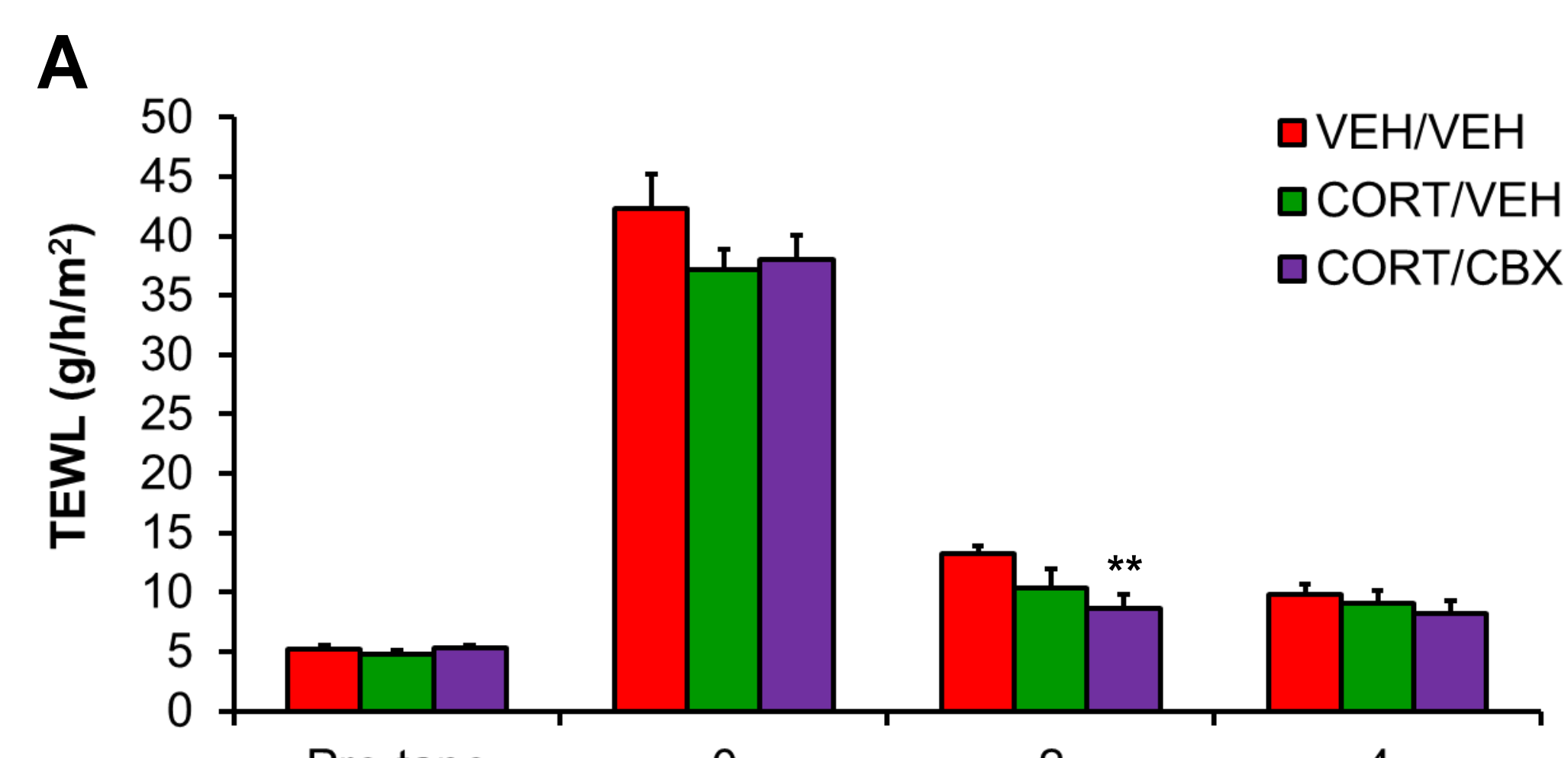

B

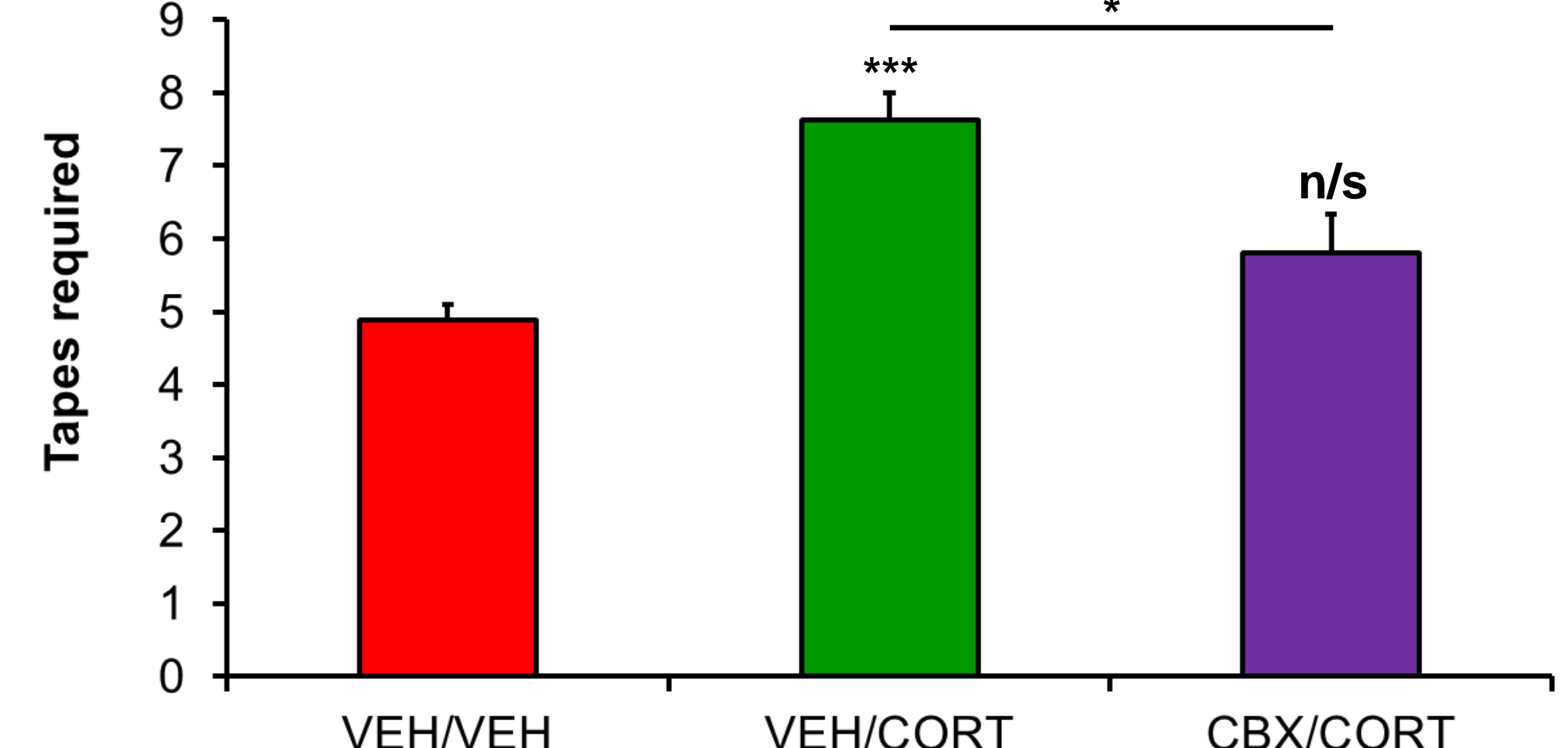

Fig. 6. CORT did not affect pre-dissumtin transepidermal water loss

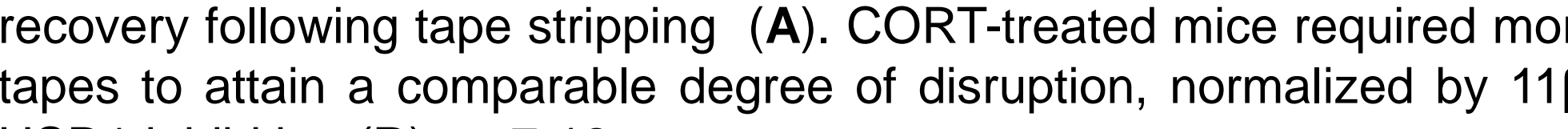

4. GCs inhibit early and drive late human keratinocyte differentiation in vitro

Primary human keratinocytes (hK) were incubated in $0.07 \mathrm{mM}$ calcium $154 \mathrm{CF}+100 \mathrm{nM}$ cortisol for $48 \mathrm{~h}$ before differentiating in $1.2 \mathrm{mM}$ calcium for $6 \mathrm{~d}$. Loricrin, and desmoglein-1 proteins (late differentiation) were elevated whereas keratin 10 (early differentiation) was lower in cortisol-treated cells (Fig. 7a, 7b). Conversely, $5 \mu \mathrm{M}$ RU486 (GR inhibitor) treatment reduced loricrin and desmoglein-1 during differentiation (Fig. 7c). 11ß-HSD1 activity also increased during differentiation
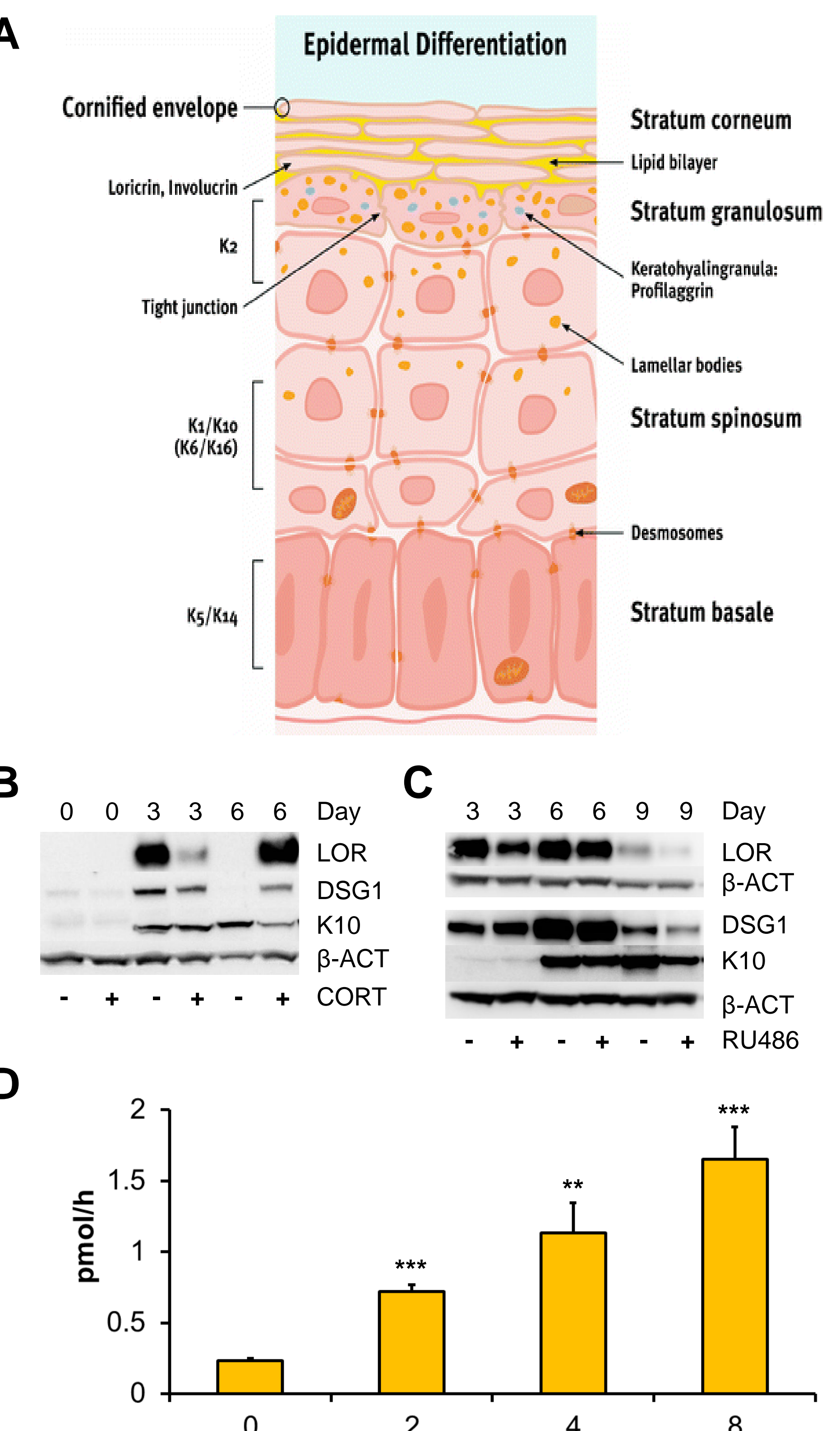

Fig. 7. (A) Epidermal differentiation process. (B) Loricrin (LOR),
desmoglein-1 (DSG1), and keratin-10 (K10) protein changes during hK 5. CBX improves WH in CORT-treated mice WH 2-4d post-wounding was unaffected by CORT or CBX treatment. From this point, no further healing was observed for CORT/VEH mice whereas CBX-treated wounds continued healing to $48 \%$ by $9 \mathrm{~d}$ compared to control wounds which healed $93 \%$ by $9 d$ (Fig. $8 a, 8 b$ ). CBX also normalized mRNA changes induced by CORT during impaired $\mathrm{WH}$ for several genes including interleukin-6, fibroblast growth factor-7 matrix metalloproteinase-9 and collagen-1 (Fig. 9). Expression of filaggrin tumor necrosis factor, interleukin- $1 \beta$ and transforming growth factor- $\beta 1$ was no regulated by CORT in unwounded skin or during $\mathrm{WH}$ (data not shown).
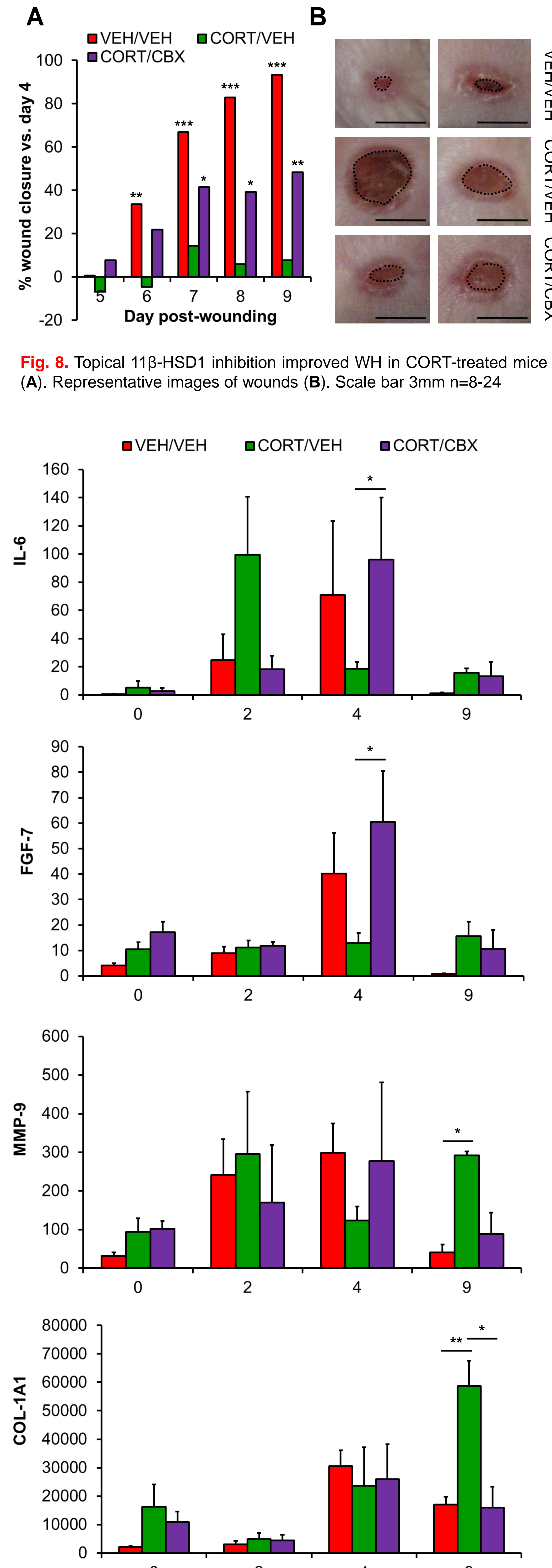

Fig. 9. 111-HSD1 blockade normalized mRNA expression of interleukin-
6 (IL-6), fibroblast growth factor-7 (FGF-7), matrix metalloprotease-
(MM-9) and collagen-1 (COL-1A1) during WH n=3-6

\section{Conclusion}

We recently demonstrated $11 \beta-H S D 1$ activity increases during mouse skin WH. Although this activity was effectively blocked with the $11 \beta$-HSD1 inhibitor CBX, measures of skin function were unaffected in control mice.

However, local CBX therapy partially reversed the effects of systemic corticosterone treatment on epidermal thickness, resistance to barrier disruption and $\mathrm{WH}$ suggesting the adverse effects of organismal GC excess (Cushing's syndrome, chronic stress) are mediated by peripheral tissue reactivation of 11-DHC/cortisone by 11ß-HSD1.

$11 \beta$-HSD1 inhibitors may be of particular benefit in older patients where increased $11 \beta$ HSD1 activity has been reported in skin Tiganescu et al. 2013, 2011) and other tissues, potentially amplifying and prolonging the effects of stress in the elderly.

\section{Publications}

Tiganescu A et al. Increased glucocorticoid activation during
mouse skin wound healing. J Endocrinol. 2014 Tiganescu A et al. 11ß-Hydroxysteroid dehydrogenase blockade prevents age-induced skin structure and function defects. $\mathbf{J ~ C l i n}$
Invest. 2013 123: 3051-60 Tiganescu A et al. Localization, age- and site-dependent type 1 in skin. J Invest Dermatol. 2011 131: 30-6 